\title{
The crossover effect of spouses' long working hours on depressive symptoms and suicidal ideation
}

\author{
Jin-Ha YOON ${ }^{1}$ and Mo-Yeol KANG ${ }^{2 *}$ \\ ${ }^{1}$ Institute for Occupational Health, College of Medicine, Yonsei University, South Korea \\ ${ }^{2}$ Department of Preventive Medicine, College of Medicine, Seoul National University, South Korea \\ Received September 12, 2015 and accepted March 16, 2016 \\ Published online in J-STAGE April 5, 2016
}

\begin{abstract}
To examine the association between spouses' weekly working hours (SWWH) and psychological symptoms such as depressive symptom and suicidal ideation. We used data from the fourth and fifth Korean National Health and Nutrition Examination Survey (2007-2012). We collected information about general characteristics, depressive symptoms, suicidal ideation, and working hours. After inclusion and exclusion criteria were applied, a sample of 8,056 house units was used for analysis. A multiple logistic regression was conducted to investigate the association between SWWH and depressive symptoms, as well as suicidal ideation, to estimate the odds ratio (OR). The relationship between SWWH and psychological symptoms were linear in husbands, and J-shaped in wives. ORs for husbands' depressive symptoms and suicidal ideation increased according to increase in SWWH ( $p$-values for trend were 0.0045 and $<0.001$, respectively). Crude ORs for wives' depressive symptoms and suicidal ideation decreased until SWWH of 40 to 49 hours, but increased after SWWH of 40 to 49 hours (all $p$-values were below 0.01). Similar trends were observed after adjustment for age, obesity, household income, and one's own weekly working hours, up to 1.33 and 1.57 in husbands, and 1.29 and 1.32 in wives, respectively. SWWH is negatively associated with mental health.
\end{abstract}

Key words: Crossover effect, Depression, Suicidal ideation, Working hours, Gender difference

\section{Introduction}

A broad body of research on impact of long working hours on workers' mental and physical health has been published ${ }^{1}$. However, limited studies have focused on the possible consequences for their intimate partners, people with whom the workers interact frequently. Many researches in the domain of occupational health psychology have shown that poor working conditions negatively influence employees' family life ${ }^{2)}$. Furthermore, not only do job stress and strain affect a person's private life intra-

*To whom correspondence should be addressed.

E-mail: snaptoon@snu.ac.kr

(C)2016 National Institute of Occupational Safety and Health individually, but their impact can also transmit to their intimate partner via crossover processes, affecting their psychological and physical health ${ }^{3)}$.

Various terms have been used to describe this phenomenon: carryover, contagion of stress, stress transmission, and stress transference. In recent years, the term 'crossover' has been used more commonly ${ }^{4}$. Previous research on multiple role stress identified two different types of stress contagion: spillover and crossover. Spillover contagion refers to a phenomenon where one's stress or strain from the work domain spills over to the family domain within a person ${ }^{5)}$. It therefore considered as an intra-individual, inter-domain transmission of stress. For instance, workers exhausted from work may feel that they have no energy to fulfil family roles as parents or spouses in the home 
domain due to their mental and physical tiredness. On the other hand, crossover contagion is viewed as a dyadic, inter-individual, inter-domain transmission of stress between closely related individuals ${ }^{3}$. For example, people who work long hours may be unhappy with their work-life imbalance, and their working patterns might have a negative impact on their domestic relationships. The stress produced by work-to-family conflict may crossover from one spouse to another. Taken together, someone's stress, which originated from their workplace, spills over to the family domain, which in turn results in increased levels of their spouse's strains. As a results, someone's long working hours can lead to spouse' mental health problems through this sequential transmission of stress.

This dyadic nature of crossover effects needs further research because it may cause negative reciprocal effects between spouses, resulting in a spiral of resource losses incurred while sustaining their well-being, and impairing the full functionality of a person ${ }^{6}$. As such, crossover is not only an important topic for researchers, but also for organizations as they try to help their employees manage their stress more effectively. In recent years, there has been an increasing amount of literature on the crossover effect between spouses, including depression ${ }^{7}$, job burnout ${ }^{3)}$, physical health ${ }^{8)}$, negative moods ${ }^{9)}$, and daily happiness ${ }^{10)}$. Most of these studies, however, have been based on data collected from participants from Western countries. As the nature of the work-family interface may vary along cultural boundaries ${ }^{11,12)}$, the interactive mechanism of the workfamily interface within a dyad that espouses Eastern values remains unclear. Therefore, these findings need to be cautiously generalized to Eastern countries. Furthermore, to our best knowledge, there is no direct evidence suggesting that an individual's long work hours could influence their spouse's mental health, such as depressive symptoms or suicidal ideation.

Given the known limitations and challenges related to the available evidence, in the present study, we investigated the crossover effect of long working hours among Korean people, particularly on spouse's mental health. The aim of this research was to examine the association between spouse's working hours and psychological symptoms using representative data from a national, populationbased survey.

\section{Subjects and Methods}

The data from the Korea National Health and Nutrition Examination Survey (KNHANES) were used for the current study. The KNHANES is being conducted by the Korea Centers for Disease Control and Prevention (KCDC) since 1998. It collects information about the participants' socioeconomic status, anthropometric measures, health interview, health examination, and nutrition survey. This yearly data is available on the KNHANES website (https:// knhanes.cdc.go.kr/knhanes/eng/index.do) ${ }^{13)}$. Interviewers asked participants about health and nutritional information and completed questionnaires were reviewed by trained staff and entered into a database.

\section{Ethics statement}

All participants of the KNHANES used in the current study provided written informed consent. This nationwide survey was approved by the Institutional Review Board (IRB) of the KCDC (IRB: 2007-02-CON-04-P; 2008-04EXP-01-C; 2009-01CON-03-2C; 2010-02CON21-C; 2011-02CON-06-C; 2012-01EXP-01-2C).

\section{Study population from KNHANES}

The KCDC conducted the $4^{\text {th }}$ KNHANES from 2007 to 2009, and the $5^{\text {th }}$ KNHANES from 2010 to 2012. Multistage probability sampling, stratified according to geographic location, sex, and age, was used. The target population of $4^{\text {th }}$ KNHANES was 31,705 , with a response rate of $78.4 \%$ and $5^{\text {th }}$ KNHANES, 33,378 with $76.5 \%$. Therefore, the initial sample consisted of 50,405 subjects $(24,871$ individuals from the $4^{\text {th }}$ KNHANES and 25,534 individuals from the $5^{\text {th }}$ KNHANES). The participants included those who were married and lived with their spouse during the KNHANES $(n=18,742)$. As we aimed to calculate the working hours of spouses or participants, we excluded those both spouses were economically inactive $(n=2,472)$. We also excluded the participants with missing values for weekly working hours (WWH), suicidal ideation, or depressive symptoms, as well as those with such missing data about their spouse $(n=158$, which means 79 house unit). Finally, 8,056 house units, totally 16,112 participants (8,056 husbands and 8,056 wives), were included in the analysis (Fig. 1).

Working hours, depressive symptoms, and suicidal ideation

Assessment of WWH (not including the time spent for meals and breaks) was obtained from self-report questionnaires. WWH as well as spouses' weekly working hours (SWWH) were categorized as follows: below 40, 40 to 49, 50 to 59 , and 60 or more hours. The question addressing depressive symptoms was, 'During the past year, did you ever feel sad or hopeless, which persisted for two weeks, 


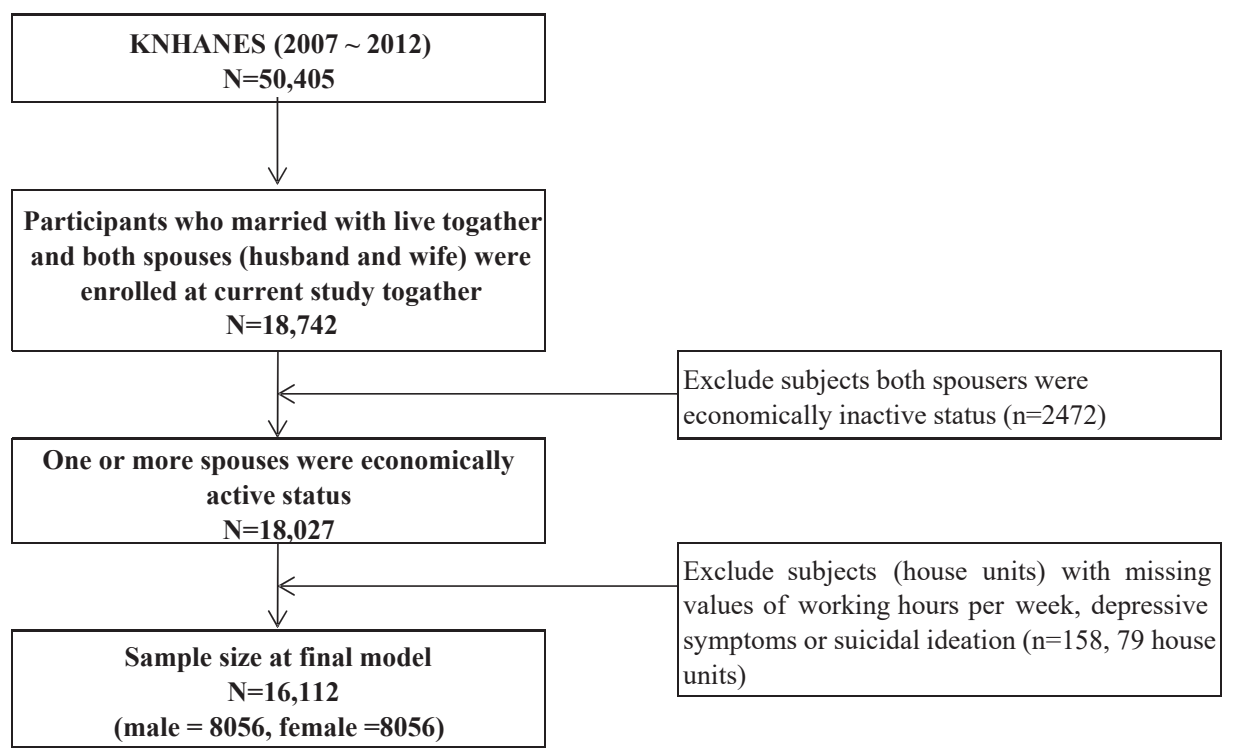

Fig. 1. Schematic diagram depicting study population.

and disrupted your social life?' The question pertaining to suicidal ideation was, 'During the past year, have you ever been willing to die?' The response options for both these questions were 'yes' and "no'

\section{Other covariates}

Household income was calculated from the total family income by adjusting for family size (number of family members who lived together). After that, income level was compared to Korean standard income levels which correspondent to 5 years age and gender stratified level. The income levels were categorized into low, middle-low, middle-high, and high income. The economically inactive was defined as people who are not in employment or unemployed. There are many reasons why an individual may be inactive, for example, they might be studying, military service, looking after family or long-term sick. The body mass index, that is, the individual's weight ( $\mathrm{kg}$ ) divided by the square of his/her height (meter), was used as the obesity parameter.

\section{Statistical analysis}

The basic characteristics were described by means and standard deviations (SD) or frequencies with percentages. The Chi-squared and t-tests were used to compare differences in basic characteristics according to the psychological symptoms (Table 1). We estimated multivariateadjusted odds ratios (ORs) and 95\% confidence intervals (95\% CIs) for depressive symptoms and suicidal ideation using logistic regression models (Table 2, 3). There were gender differences in association between spouse's weekly working hours and psychological symptoms. The lowest prevalence of psychological symptoms was observed when spouse's weekly working hours was economically inactive in men and 40 to 49 hours in women. Hence, we undertook further analyses using gender stratification methods. Model I was adjusted for age, body mass index, and household income, and Model II was further adjusted for the participant's own WWH. The $p$-values for trends about the risk of psychological symptoms according to SWWH were calculated as well (Table 2 and 3). Two-tailed $p$-values less than 0.05 were considered statistically significant. All analyses were performed with the SAS software (ver. 9.2).

\section{Results}

Basic characteristics of participants according to psychological symptoms

Results for basic characteristics according to depressive symptoms and suicidal ideation have been presented in Table 1. Note that $8.5 \%(n=688)$ and $9.2 \%(n=744)$ of the husbands experienced depressive symptoms and suicidal ideation, respectively. On the other hand, $15.5 \%$ $(n=1,248)$ and $16.5 \%(n=1,329)$ of the wives experienced depressive symptoms and suicidal ideation, respectively. In both the genders, those who reported of having depressive symptoms and suicidal ideation were older than those who did not. The BMI of the suicidal ideation group was lower than that of the others in males, but higher in females $(23.8 \pm 3.1$ and $24.2 \pm 3$ in males, and $23.8 \pm 3.7$ 
Table 1. Basic characteristics of study population

Mean (SD) or n (\%)

\begin{tabular}{|c|c|c|c|c|c|c|c|}
\hline & \multicolumn{3}{|c|}{ Depressive symptoms } & \multicolumn{4}{|c|}{ Suicidal ideation } \\
\hline & Total & Yes & No & & Yes & No & \\
\hline \multicolumn{8}{|l|}{ Male } \\
\hline Age & $50.2 \pm 12.6$ & $52.3 \pm 12.6$ & $50 \pm 12.6$ & $p<0.01 ; \mathrm{t}=4.61$ & $53.8 \pm 13.2$ & $49.8 \pm 12.5$ & $p<0.01 ; \mathrm{t}=-7.81$ \\
\hline Body mass index & $24.2 \pm 3$ & $24 \pm 3.1$ & $24.2 \pm 3$ & $P=0.15 ; \mathrm{t}=-1.40$ & $23.8 \pm 3.1$ & $24.2 \pm 3$ & $P=0.15 ; \mathrm{t}=4.02$ \\
\hline \multicolumn{8}{|l|}{ House hold income level } \\
\hline 1st quartile & $974(12.2)$ & $127(13.0)$ & $847(87.0)$ & \multirow[t]{4}{*}{$p<0.01 ; x^{2}=38.33$} & $154(15.8)$ & $820(84.2)$ & \multirow[t]{4}{*}{$p<0.01 ; x^{2}=97.03$} \\
\hline 2nd quartile & $1,989(24.9)$ & $185(9.3)$ & $1,803(90.7)$ & & $234(11.8)$ & $1,755(88.2)$ & \\
\hline 3rd quartile & $2,458(30.8)$ & $186(7.6)$ & $2,272(92.4)$ & & $176(7.2)$ & $2,282(92.8)$ & \\
\hline 4th quartile & $2,564(32.1)$ & $178(6.9)$ & $2,386(93.1)$ & & $173(6.7)$ & $2,391(93.3)$ & \\
\hline \multicolumn{8}{|c|}{ One's own weekly working hours } \\
\hline Economically inactive & $538(6.7)$ & $75(14.0)$ & $462(86.0)$ & \multirow[t]{5}{*}{$p<0.01 ; x^{2}=30.20$} & $95(17.7)$ & $443(82.3)$ & \multirow[t]{5}{*}{$p<0.01 ; x^{2}=83.05$} \\
\hline$<40$ hours & $1,426(17.7)$ & $116(8.1)$ & $1,310(91.9)$ & & $149(10.4)$ & $1,277(89.6)$ & \\
\hline $40-50$ hours & $2,672(33.2)$ & $199(7.4)$ & $2,473(92.6)$ & & $174(6.5)$ & $2,498(93.5)$ & \\
\hline $50-60$ hours & $1,456(18.1)$ & $108(7.4)$ & $1,348(92.6)$ & & $111(7.6)$ & $1,345(92.4)$ & \\
\hline$\geq 60$ hours & $1,964(24.4)$ & $190(9.7)$ & $1,774(90.3)$ & & $215(10.9)$ & $1,749(89.1)$ & \\
\hline \multicolumn{8}{|c|}{ Spouse's weekly working hours } \\
\hline Economically inactive & $3,485(43.3)$ & $260(7.5)$ & $3,225(92.5)$ & \multirow[t]{5}{*}{$p<0.01 ; x^{2}=16.40$} & $246(7.1)$ & $3,239(92.9)$ & \multirow[t]{5}{*}{$p<0.01 ; x^{2}=41.51$} \\
\hline$<40$ hours & $1,747(21.7)$ & $162(9.3)$ & $1,585(90.7)$ & & $186(10.6)$ & $1,561(89.4)$ & \\
\hline $40-50$ hours & $1,378(17.1)$ & $126(9.1)$ & $1,252(90.9)$ & & $135(9.8)$ & $1,243(90.2)$ & \\
\hline $50-60$ hours & $553(6.9)$ & $40(7.2)$ & $513(92.8)$ & & $61(11.0)$ & $492(89.0)$ & \\
\hline$\geq 60$ hours & $893(11.1)$ & $100(11.2)$ & $792(88.8)$ & & $116(13.0)$ & $777(87.0)$ & \\
\hline \multicolumn{8}{|l|}{ Female } \\
\hline Age & $47 \pm 12.1$ & $49.1 \pm 12.2$ & $46.7 \pm 12$ & $p<0.01 ; \mathrm{t}=6.55$ & $49.3 \pm 13.2$ & $46.6 \pm 11.8$ & $P<0.01 ; \mathrm{t}=-6.87$ \\
\hline Body mass index & $23.5 \pm 3.4$ & $23.7 \pm 3.6$ & $23.5 \pm 3.4$ & $P=0.05 ; \mathrm{t}=1.95$ & $23.8 \pm 3.7$ & $23.5 \pm 3.3$ & $p<0.01 ; \mathrm{t}=-2.84$ \\
\hline \multicolumn{8}{|l|}{ House hold income level } \\
\hline 1st quartile & $974(12.2)$ & $215(22.1)$ & $759(77.9)$ & \multirow[t]{4}{*}{$p<0.01 ; x^{2}=41.31$} & $247(25.4)$ & $727(74.6)$ & \multirow[t]{4}{*}{$p<0.01 ; \mathrm{x}^{2}=105.3$} \\
\hline 2nd quartile & $1,989(24.9)$ & $317(15.9)$ & $1,672(84.1)$ & & $376(18.9)$ & $1,613(81.1)$ & \\
\hline 3rd quartile & $2,458(30.8)$ & $354(14.4)$ & $2,103(85.6)$ & & $391(15.9)$ & $2,067(84.1)$ & \\
\hline 4th quartile & $2,564(32.1)$ & $350(13.7)$ & $2,212(86.3)$ & & $303(11.8)$ & $2,261(88.2)$ & \\
\hline \multicolumn{8}{|c|}{ One's own weekly working hours } \\
\hline Economically inactive & $3,483(43.2)$ & $542(15.6)$ & $2,940(84.4)$ & \multirow[t]{5}{*}{$p<0.01 ; x^{2}=21.77$} & $590(16.9)$ & $2,893(83.1)$ & \multirow[t]{5}{*}{$p<0.01 ; x^{2}=30.65$} \\
\hline$<40$ hours & $1,746(21.7)$ & $261(15)$ & $1,483(85)$ & & $285(16.3)$ & $1,461(83.7)$ & \\
\hline $40-50$ hours & $1,380(17.1)$ & $176(12.8)$ & $1,204(87.2)$ & & $168(12.2)$ & $1,212(87.8)$ & \\
\hline $50-60$ hours & $556(6.9)$ & $92(16.5)$ & $464(83.5)$ & & $107(19.2)$ & $449(80.8)$ & \\
\hline$\geq 60$ hours & $891(11.1)$ & $177(19.9)$ & $714(80.1)$ & & $179(20.1)$ & $712(79.9)$ & \\
\hline \multicolumn{8}{|c|}{ Spouse's weekly working hours } \\
\hline Economically inactive & $540(6.7)$ & $97(18)$ & $443(82)$ & \multirow[t]{5}{*}{$p<0.01 ; x^{2}=20.49$} & $110(20.4)$ & $430(79.6)$ & \multirow[t]{5}{*}{$p<0.01 ; \mathrm{x}^{2}=22.28$} \\
\hline$<40$ hours & $1,429(17.7)$ & 243 (17) & $1,186(83)$ & & $258(18.1)$ & $1,171(81.9)$ & \\
\hline $40-50$ hours & $2,669(33.1)$ & $357(13.4)$ & $2,310(86.6)$ & & $373(14)$ & $2,296(86)$ & \\
\hline $50-60$ hours & $1,454(18.1)$ & $210(14.5)$ & $1,243(85.5)$ & & $244(16.8)$ & $1,210(83.2)$ & \\
\hline$\geq 60$ hours & $1,964(24.4)$ & $341(17.4)$ & $1,623(82.6)$ & & $344(17.5)$ & $1,620(82.5)$ & \\
\hline
\end{tabular}

and $23.5 \pm 3.3$ in females, in the suicidal ideation group and the others, respectively. Both $p$-values were below 0.01). In addition, there was an inverse relationship between the quartile levels of household income and the psychological symptoms. Specifically, the proportion of depressive symptoms and suicidal ideation in the $1^{\text {st }}$ quartile household income group was $13.3 \%$ and $22.1 \%$, respectively, in husbands, and $15.8 \%$ and $25.4 \%$, respectively, in wives. Further, these proportions in the $1^{\text {st }}$ quartile household income group were higher than those observed in the other quartiles of household income (all $p$-values were below 0.01).

For husbands, the proportion of depressive symptoms and suicidal ideation in the economically inactive population was $14.0 \%$ and $17.1 \%$, respectively, and these proportions were greater than those observed for all the WWH groups. The economically inactive group was followed by the 60 or more WWH group. The lowest proportion of 
Table 2. Odds ratio (95\% confidence interval) of depressive symptoms

\begin{tabular}{|c|c|c|c|}
\hline & Crude model & model I & model II \\
\hline \multicolumn{4}{|l|}{ Male } \\
\hline \multicolumn{4}{|l|}{ Spouse's weekly working hours } \\
\hline Economically inactive & $1-$ & $1-$ & $1-$ \\
\hline$<40$ hours & $1.17(0.94-1.45)$ & $1.13(0.91-1.42)$ & $1.14(0.91-1.43)$ \\
\hline $40-50$ hours & $1.12(0.88-1.42)$ & $1.15(0.90-1.47)$ & $1.15(0.90-1.46)$ \\
\hline $50-60$ hours & $1.00(0.70-1.44)$ & $0.94(0.65-1.36)$ & $0.95(0.66-1.37)$ \\
\hline$\geq 60$ hours & $1.47(1.14-1.91)$ & $1.38(1.05-1.81)$ & $1.33(1.01-1.74)$ \\
\hline$p$ for trend & 0.0159 & 0.045 & 0.1035 \\
\hline \multicolumn{4}{|l|}{ One's own weekly working hours } \\
\hline$<40$ hours & & & $0.94(0.73-1.21)$ \\
\hline $40-50$ hours & & & $1-$ \\
\hline $50-60$ hours & & & $0.99(0.77-1.26)$ \\
\hline$\geq 60$ hours & & & $1.2(0.97-1.49)$ \\
\hline \multicolumn{4}{|l|}{ Female } \\
\hline \multicolumn{4}{|l|}{ Spouse's weekly working hours } \\
\hline Economically inactive & $1.46(1.11-1.91)$ & $1.25(0.93-1.68)$ & $1.23(0.92-1.66)$ \\
\hline$<40$ hours & $1.22(0.95-1.57)$ & $1.07(0.82-1.39)$ & $1.08(0.83-1.40)$ \\
\hline $40-50$ hours & $1-$ & $1-$ & $1-$ \\
\hline $50-60$ hours & $1.11(0.86-1.44)$ & $1.08(0.84-1.40)$ & $1.06(0.82-1.37)$ \\
\hline$\geq 60$ hours & $1.44(1.16-1.79)$ & $1.39(1.11-1.74)$ & $1.29(1.03-1.62)$ \\
\hline$p$ for trend, 50 hours or below & 0.0058 & 0.1999 & 0.2414 \\
\hline$p$ for trend, 50 hours or above & 0.0018 & 0.0059 & 0.0445 \\
\hline \multicolumn{4}{|l|}{ One's own weekly working hours } \\
\hline$<40$ hours & & & $1.15(0.93-1.42)$ \\
\hline $40-50$ hours & & & $1-$ \\
\hline $50-60$ hours & & & $1.29(0.97-1.70)$ \\
\hline$\geq 60$ hours & & & $1.53(1.21-1.94)$ \\
\hline
\end{tabular}

Model I : adjusted for age, body mass index, house hold income

Model II: Model I+adjusted for my working hours per week

depressive symptoms and suicidal ideation was observed in the 40 to 49 WWH group.

For wives, the proportion of depressive symptoms and suicidal ideation in the 40 to $40 \mathrm{WWH}$ group was $12.8 \%$ and $12.2 \%$, respectively, which were the lowest across all WWH groups. The greatest proportion of both the psychological symptoms was observed in the 60 or more WWH group, which was followed by the economically inactive group.

Linear and J shaped relationship between SWWH and psychological symptoms

The proportion of depressive symptoms and suicidal ideation in husbands was greatest in the 60 hours or more SWWH (11.2\% and 13.0\%, respectively, refer Fig. 2). The proportion of both these psychological symptoms increased with an increase in the SWWH ( $p$-values for both the trends were below 0.001) (Fig. 2).

In the wives, however, there was a $\mathrm{J}$ shaped relationship between SWWH and proportion of psychological symp- toms. The proportion of depressive symptoms and suicidal ideation was the greatest in the group with the economically inactive spouse (18.0\% and $20.4 \%$, respectively). In addition, the proportion of both the psychological symptoms decreased until 40 to 49 SWWH ( $p$-values for both the trends were below 0.001); while it increased after 40 to $49 \mathrm{SWWH}$ ( $p$-value was below 0.001 for the depressive symptoms, and 0.001 for suicidal ideation, (Fig. 2).

Odds ratios with $95 \%$ confidence interval of depressive symptoms

The OR $(95 \%$ CI) for depressive symptoms in husbands was $1.47(1.14-1.1)$ in the 60 or more SWWH, as compared to that in the group with the economically inactive spouse (Table 2). Adjustment for age, BMI, household income, and participant's WWH did not attenuate this association in Model II (OR: 1.33, 95\% CI: 1.01-1.74). The ORs increased with increase in SWWH in the crude model and Model I logistic regression analysis ( $p$-values for trends were 0.0159 in the crude model and 0.045 in 
Table 3. Odds ratio ( $95 \%$ confidence interval) of suicidal ideation

\begin{tabular}{|c|c|c|c|}
\hline & Crude model & model I & Model II \\
\hline \multicolumn{4}{|l|}{ Male } \\
\hline \multicolumn{4}{|l|}{ Spouse's weekly working hours } \\
\hline Economically inactive & $1-$ & $1-$ & $1-$ \\
\hline$<40$ hours & $1.39(1.12-1.72)$ & $1.29(1.03-1.60)$ & $1.29(1.04-1.61)$ \\
\hline $40-50$ hours & $1.28(1.01-1.62)$ & $1.31(1.03-1.66)$ & $1.33(1.05-1.69)$ \\
\hline $50-60$ hours & $1.48(1.08-2.04)$ & $1.33(0.95-1.84)$ & $1.31(0.95-1.83)$ \\
\hline$\geq 60$ hours & $1.91(1.49-2.44)$ & $1.67(1.29-2.15)$ & $1.57(1.21-2.03)$ \\
\hline$p$ for trend & $<0.001$ & $<0.001$ & 0.001 \\
\hline \multicolumn{4}{|l|}{ One's own weekly working hours } \\
\hline$<40$ hours & & & $1.26(0.98-1.6)$ \\
\hline $40-50$ hours & & & $1-$ \\
\hline $50-60$ hours & & & $1.14(0.89-1.46)$ \\
\hline$\geq 60$ hours & & & $1.52(1.23-1.89)$ \\
\hline \multicolumn{4}{|l|}{ Female } \\
\hline \multicolumn{4}{|l|}{ Spouse's weekly working hours } \\
\hline Economically inactive & $1.73(1.33-2.25)$ & $1.2(0.90-1.6) 0$ & $1.17(0.88-1.57)$ \\
\hline$<40$ hours & $1.29(1.01-1.65)$ & $1.01(0.78-1.31)$ & $1.01(0.78-1.31)$ \\
\hline $40-50$ hours & $1-$ & $1-$ & $1-$ \\
\hline $50-60$ hours & $1.29(1.01-1.65)$ & $1.23(0.95-1.59)$ & $1.19(0.92-1.54)$ \\
\hline$\geq 60$ hours & $1.50(1.21-1.87)$ & $1.40(1.12-1.75)$ & $1.32(1.05-1.66)$ \\
\hline$p$ for trend, 50 hours or below & $<0.001$ & 0.224 & 0.2749 \\
\hline$p$ for trend, 50 hours or above & $<0.001$ & 0.002 & 0.0202 \\
\hline \multicolumn{4}{|l|}{ One's own weekly working hours } \\
\hline$<40$ hours & & & $1.27(1.03-1.56)$ \\
\hline $40-50$ hours & & & $1-$ \\
\hline $50-60$ hours & & & $1.56(1.19-2.05)$ \\
\hline$\geq 60$ hours & & & $1.54(1.21-1.95)$ \\
\hline
\end{tabular}

Model I : adjusted for age, body mass index, house hold income

Model II: Model I+ adjusted for my working hours per week

Male, spouse's weekly working hours and psychological symptoms

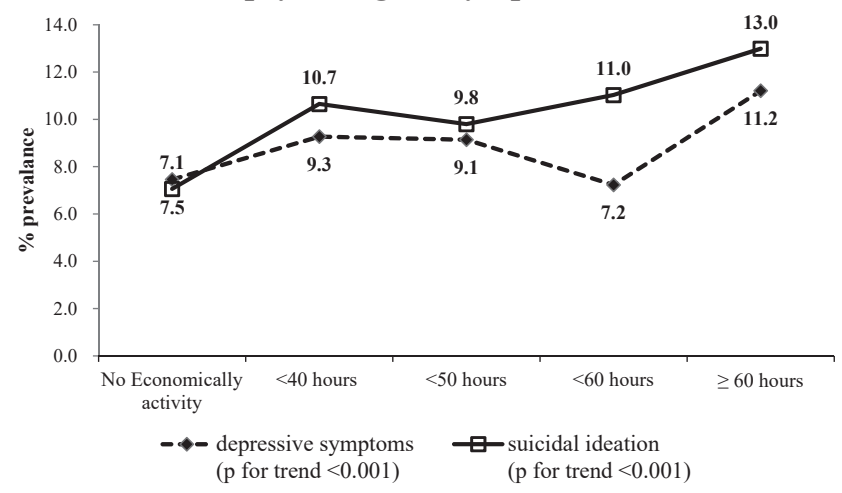

Female, spouse's weekly working hours and psychological symptoms

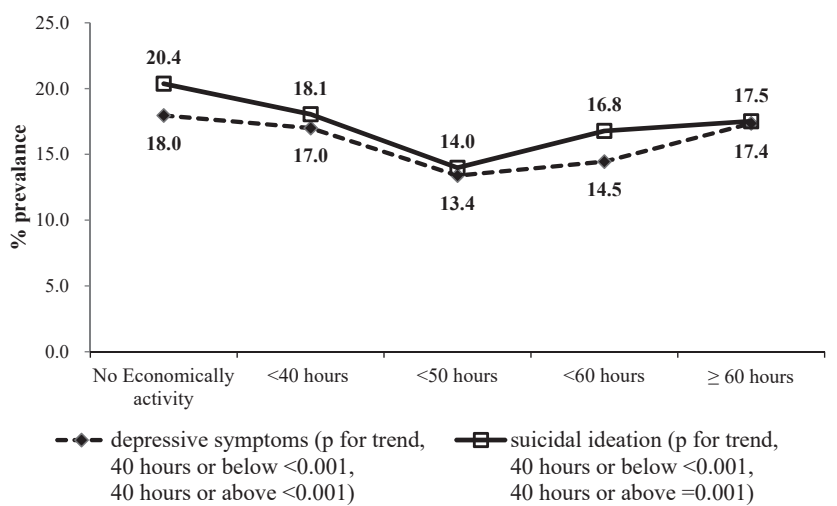

Fig. 2. Prevalence of psychological symptoms (depressive symptoms and suicidal ideation) according to spouse's working hours per week.

Model I).

For the wives, the ORs $(95 \% \mathrm{CI})$ of depressive symptoms were $1.46(1.11-1.91)$ in the group with the economically inactive spouse and $1.44(1.16-1.79)$ in the 60 or more SWWH, as compared to that in the 40 to $49 \mathrm{SWWH}$ group. The OR for depressive symptoms in the group with the economically inactive spouse lost its significance after it was adjusted for age, BMI, and household income. How- 
ever, adjustment of age, BMI, household income, as well as participant's WWH did not attenuate the statistical significance of the OR in 60 or more SWWH (OR: 1.29, 95\% CI: $1.03-1.2)$. The $p$-value for the trend of increase in the OR for depressive symptoms after 40 to $49 \mathrm{SWWH}$ was 0.0445 SWWH in Model II.

Odds ratios with $95 \%$ confidence interval of suicidal ideation

Suicidal ideation increased with increase in SWWH in the crude logistic regression model for the husbands ( $p$-value for the trend was below 0.001). The ORs increased with increase in SWWH, as compared to that in the group with an economically inactive spouse. Further adjustment for age, BMI, household income and participant's WWH did not attenuate this association, except in the 50 to 59 SWWH group [OR $(95 \%$ CI), $1.29(1.04-1.61)$ in below 40 hours group; $1.33(1.05-1.69)$ in the 40 to 49 hours group; $1.57(1.21-2.03)$ in the 60 or more SWWH]. The ORs increased with increase in SWWH, and the $p$-value for this trend was 0.001 in Model II.

For the wives, the ORs for suicidal ideation increased in all SWWH groups, except for the 40 to 49 hours group SWWH [OR $(95 \% \mathrm{CI}), 1.73(1.33-2.25)$ in the group with an economically inactive spouse; $1.29(1.01-1.65)$ in the below 40 hours group; $1.29(1.01-1.65)$ in the 50 to 59 hours group; and $1.50(1.21-1.87)$ in the 60 or more SWWH group]. Further adjustment somewhat attenuated the association, but the OR $(95 \% \mathrm{CI})$ for the 60 or more SWWH was $1.32(1.05-1.66)$ in Model II. The $p$-values for the trend for groups with 50 hours or more SWWH was below 0.001, 0.002, and 0.0202, in the crude model, Model I, and Model II, respectively.

\section{Discussion}

The primary objective of this study was to examine the association between SWWH and psychological symptoms, such as depressive symptom and suicidal ideation. The results of this study showed that SWWH was significantly associated with individuals' risk for depressive symptom and suicidal ideation. These findings indicate that individual's long working hours have adverse effects, not only on their own mental health, but also on that of their spouses.

Our findings are in line with those of previous studies. For instance, using structural equation modelling analysis, Westman and Vinokur demonstrated that the correlation between depression symptoms of couples was significant $^{14)}$. Hammer et al. also found that the crossover effect of a husband's work interfered with family conflict and his wife's depression ${ }^{7)}$. Similarly, Matthews et al. examined the work-to-relationship conflict experienced by individuals, and perceptions of their spouse's work-to-relationship conflict, in both members of 113 dual-earner couples ${ }^{15}$. The results suggested that work-to-relationship conflict and perceptions of spouse's work-to-family conflict were related to spouses' relationship tension, health symptoms, and relationship satisfaction. A study on Japanese dualearner couples revealed that dual experiences of work-tofamily conflict and family-to-work conflict had adverse associations with the psychological health of employees and the relationship quality between spouses of both genders ${ }^{16)}$. In addition, it was observed that dual experiences in husbands was adversely associated with the psychological health of their spouses (i.e., wives), whereas this was not the case for wives. More recently, Kramer and Chung reported relationship between spouse work hours and BMI growth over time in dual-earners families ${ }^{17}$. Drawing on conservation of resources theory, authors proposed that an increase in demands - both in the work realm (e.g., the number of work hours) and in the family realm (e.g., the number of spouse work hours) - is likely to speed up the increase of BMI.

There were numerous articles about the association between long working hours and symptoms of depression $^{18,19)}$. Kim et al. (2013) et al. found a substantial relationship between working hours and depressive symptomatology ${ }^{18)}$ using representative national data in Korea, and a cohort study using Whitehall II data revealed that every 10 -hour increase in working hours is related to a $17 \%$ increase in depressive symptoms ${ }^{19)}$. These studies suggested that long working hours may affect mental health through insufficient recovery after work ${ }^{20)}$, high job demands ${ }^{21)}$, and work-family conflict ${ }^{22)}$. Our results are also in accordance with previous findings, even though main topic of our study was effects of spouses' working hours (Table 2 and 3). When we took into account the role of one's own working hours as well as their spouse's working hours on one's own mental health, it seemed that each of working hours independently affect depressive symptoms and suicidal ideation ( $p$-interaction between spouse's and own working hours: depressive symptoms, male $=0.191$, female $=0.968$; suicidal ideation, male $=0.391$, female $=0.958$ )

Westman suggested three possible mechanisms to explain the crossover process ${ }^{3)}$. First, the direct transmission of strain, where one's strain produces an empathetic reaction in the other spouse, increasing his/her level of 
strain. Since spouses spend considerable time together, they may pay close attention to, and be affected by others' emotional states. Second, spouses may share some common stressors (e.g., financial pressures, life events) that can affect both members of the dyad simultaneously. Third, crossover effect may occur through an indirect process in which the transmission of strain be mediated by negative social interactions and communication (e.g., social undermining and lack of social support).

Of these mechanisms, the common stressors mechanism can explain a lot about our finding that unemployment of husbands increase wives' risk of depressive symptoms. Westman and Vinokur suggested that common stressful life events increased depression in both spouses ${ }^{14)}$. The results of the present study regarding unemployment of the spouse and depressive symptoms showed that the spouse's unemployment was associated with depressive symptoms. This result is in line with previous studies that have found that couples' economic difficulties affected the perceived health of both spouses ${ }^{8)}$. Depressive symptoms caused by job loss or sudden retirement would certainly affect the spouse $^{23)}$ and be linked with spouses' depressive symptoms for couples in which both partners felt close to each other $^{24)}$. It is referred to as depression contagion ${ }^{25)}$. It was revealed that an individual's underemployment may influence both spouses' moods through this mechanism ${ }^{26}$. It is possible that income reduction due to underemployment is an important factor that affects the mental health of a person and their spouse.

In current study, individual's perceived stress level was significantly correlated with spouse's perceived stress level in both male and female (male, $\beta=0.1085, p$ value $<0.001$; female, $\beta=0.1089, p$ value $<0.001)$. These results can be explained by direct transmission of strain. Recent studies have addressed the communication of emotions plays an important role in this respect, such as the spillover effects of among family members ${ }^{27)}$ or crossover effects of unemployment between a couple ${ }^{3)}$. However, life style or family role in home domain could also affect the stress response and eventually process of depressive symptom development, but we could not take it into account because of lack of information regarding origin of strain (from work or family domain). Poor self-esteem or the threshold of each individual coping with the stress should be considered as well ${ }^{28)}$.

The results obtained from our analysis by gender have shown that husbands have decreased risk for mental health problems as their wives work less hours, but wives are more likely to have poorer mental health when their hus- bands do not work (Table 2 and 3). Gender role stereotypes are important to understand the work-family conflict. The traditional gender role expectation assumes that the family domain, in comparison to the work domain, is the most important life domain for women, while men feel primarily responsible for the work role, and attach greater value to the work domain ${ }^{29}$. Our findings that psychological symptoms increased in wives whose husbands were economically inactive are in line with the traditional gender role expectation. Moreover, it is known as husbands tended to receive much more mental and physical support from their wives; however, the wives did not receive much support from their husbands ${ }^{30}$. Due to the differences in the support between husband and wife, effect of SWWH on mental health might be more prominent among male than female.

These gender differences in response to SWWH can be explained, in part, by the East Asian cultural climate. The East Asian culture encourages employees, particularly men, to devote long hours at work, for the benefit of the family. Because daily life in these countries is influenced by a collectivistic cultural value ${ }^{31)}$, gender roles under the patriarchal Confucianism are common in East Asian couples $^{32)}$, and in these roles, men who only concentrated on career tend to depend more on their wives in family domain ${ }^{33)}$. According to this family-based work ethic, working, and temporarily sacrificing family life would be tolerated by the family members as a necessary evil, or is regarded as a self-sacrifice made for the benefit of the family ${ }^{31)}$. Although the distinction of cultural gender roles has become ambiguous due to the increased economic activity of women, the women in Korea still fulfill cultural gender roles, in general. Almost half of female participants of study population were housewives who are economically inactive and they usually take care of their husbands and children in home.

However, economic pressures are forcing women to take a more active role outside the home and to pursue fulltime careers in Korea ${ }^{34)}$. Women are increasingly being forced to deal with rising expectations and job demands that limit their performance related to family roles. Similarly, men are becoming more involved with their families, and their priorities may even be shifting away from work. The increasing participation of women in the workforce, and a greater number of dual-earner families, has made traditional approaches to coordinating work and family lives inappropriate. In our analysis only among dual-earners families, the SWWH have significant relationship with increased risk of psychological symptoms, especially in women (Supplementary Table 1). Spouse's long working 
hours may worsen domestic situation to other family members (e.g., less time for leisure activities at home together) and therefore can result in adverse mental health. Together, these trends result in the potential for interference or conflicts between peoples' work and non-work lives.

The current research has several methodological shortcomings that must be kept in mind when interpreting the results. First, the cross-sectional design of our study did not allow us to draw conclusions regarding the causal nature of the relationship between one spouse's long working hours and the other's psychological problems. A reverse causality cannot be overruled, especially in people who were more likely to spend longer hours in the workplace due to their spouse's psychological symptoms. Analysis of longitudinal data would allow further exploration of the questions raised by this study. Second, under-reporting of suicidal ideation or depressive symptom is probable because Korean people tend to hide their psychological problems due to worries related to loss of social reputation. Third, only two questions were used to assess psychological symptoms in our study, and both of them were just yes or no question. However, there is evidence that the two-item short version of the Patient Health Questionnaire's depression module (PHQ-2) is correlated with the 9-item version (PHQ-9) ${ }^{35)}$. The two items on the PHQ-2 are similar to our depressive symptoms questions. Depressive symptom persisting for more than two weeks and suicidal ideation are essential aspect for the diagnosis of major depressive dis$\operatorname{order}^{36)}$. Furthermore, when we conducted dyadic analysis for a binary outcome using nonlinear mixed effect model ${ }^{37)}$ to consider the spouses' effect on each other in our data context, the results showed that estimated coefficients of spouse's long time work $(\mathrm{SWWH}>60)$ for depressive symptoms and suicidal ideation were 0.3572 and 0.3277 , respectively ( $p$-value $<0.001$, both). This suggests that SWWH had significant effect on the probability of depressive symptoms and suicidal ideations, taking into account the other predictors and the random variance. Finally, although our study showed association between SWWH and psychological symptoms, the mechanisms behind our findings are not clearly tested. More research on this topic is needed before we can clearly understand the mechanism by which SWWH affect mental health.

The most important conclusion of this study may be that individual's long working hours are more than a workrelated problem; they appear to be a family-related problem as well. Our finding showed associations between long working hours and spouse's psychological symptoms. Therefore, reducing working hours may not only contrib- ute to reducing workers' own mental health problems, but also those of their spouses. We hope that organizations also acknowledge this finding and take it into account when developing human resource management policies. For example, organizations may consider stress interventions targeting couple dyads, such as Couples Coping Enhancement Training, which is considered an effective training method based on the systematic-transactional coping approach in couples ${ }^{38)}$.

\section{References}

1) Caruso CC HE, Dick RB, Russo JM, Schmit JM. Overtime and extended work shifts: recent findings on illnesses, injuries, and health behaviors: US Department of Health and Human Services, Centers for Disease Control and Prevention, National Institute for Occupational Safety and Health; 2004.

2) Bianchi SM, Milkie MA (2010) Work and family research in the first decade of the 21 st century. J Marriage Fam 72, $705-25$.

3) Westman M (2001) Stress and strain crossover. Hum Relat 54, 717-51.

4) Crossfield S, Kinman G, Jones F (2005) Crossover of occupational stress in dual-career couples: The role of work demands and supports, job commitment and marital communication. Community Work Fam 8, 211-32.

5) Bakker AB, Demerouti E, Schaufeli WB (2005) The crossover of burnout and work engagement among working couples. Hum Relat 58, 661-89.

6) Westman M, Brough P, Kalliath T (2009) Expert commentary on work-life balance and crossover of emotions and experiences: Theoretical and practice advancements. J Organ Behav 30, 587-95.

7) Hammer LB, Cullen JC, Neal MB, Sinclair RR, Shafiro MV (2005) The longitudinal effects of work-family conflict and positive spillover on depressive symptoms among dualearner couples. J Occup Health Psychol 10, 138-54.

8) Westman M, Keinan G, Roziner I, Benyamini Y (2008) The crossover of perceived health between spouses. J Occup Health Psychol 13, 168-80.

9) Song Z, Foo MD, Uy MA (2008) Mood spillover and crossover among dual-earner couples: a cell phone event sampling study. J Appl Psychol 93, 443-52.

10) Rodríguez-Muñoz A, Sanz-Vergel AI, Demerouti E, Bakker AB (2014) Engaged at work and happy at home: A spillover-Crossover model. J Happiness Stud 15, 271-83.

11) Ford MT, Heinen BA, Langkamer KL (2007) Work and family satisfaction and conflict: a meta-analysis of crossdomain relations. J Appl Psychol 92, 57-80.

12) Zhang M, Foley S, Yang B (2013) Work-family conflict among Chinese married couples: testing spillover and crossover effects. Int J Hum Resour Manage 24, 3213-31.

13) Kweon S, Kim Y, Jang MJ, Kim Y, Kim K, Choi S, Chun C, 
Khang YH, Oh K (2014) Data resource profile: the Korea National Health and Nutrition Examination Survey (KNHANES). Int J Epidemiol 43, 69-77. doi:10.1093/ije/ dyt228. PubMed PMID: 24585853; PubMed Central PMCID: PMC3937975.

14) Westman M, Vinokur AD (1998) Unraveling the relationship of distress levels within couples: Common stressors, empathic reactions, or crossover via social interaction? Hum Relat 51, 137-56.

15) Matthews RA, Del Priore RE, Acitelli LK, Barnes-Farrell JL (2006) Work-to-relationship conflict: crossover effects in dual-earner couples. J Occup Health Psychol 11, 228-40.

16) Shimazu A, Kubota K, Bakker A, Demerouti E, Shimada K, Kawakami N (2013) Work-to-family conflict and family-towork conflict among Japanese dual-earner couples with preschool children: a spillover-crossover perspective. J Occup Health 55, 234-43.

17) Kramer A, Chung W. Work Demands, Family Demands, and BMI in Dual-Earners Families: A 16-Year Longitudinal Study. 2015.

18) Kim I, Kim H, Lim S, Lee M, Bahk J, June KJ, Kim S, Chang WJ (2013) Working hours and depressive symptomatology among full-time employees: Results from the fourth Korean National Health and Nutrition Examination Survey (2007-2009). Scand J Work Environ Health 39, 515-20.

19) Virtanen M, Ferrie JE, Singh-Manoux A, Shipley MJ, Stansfeld SA, Marmot MG, Ahola K, Vahtera J, Kivimäki M (2011) Long working hours and symptoms of anxiety and depression: a 5-year follow-up of the Whitehall II study. Psychol Med 41, 2485-94.

20) Geurts SA, Sonnentag S (2006) Recovery as an explanatory mechanism in the relation between acute stress reactions and chronic health impairment. Scand J Work Environ Health 32, 482-92.

21) van der Hulst M, van Veldhoven M, Beckers D (2006) Overtime and need for recovery in relation to job demands and job control. J Occup Health 48, 11-9.

22) Golden L, Wiens-Tuers B (2006) To your happiness? Extra hours of labor supply and worker well-being. J Socio-Economics 35, 382-97.

23) Szinovacz ME, Davey A (2004) Retirement transitions and spouse disability: effects on depressive symptoms. J Gerontol B Psychol Sci Soc Sci 59, S333-42.

24) Tower RB, Kasl SV (1996) Depressive symptoms across older spouses: longitudinal influences. Psychol Aging 11, 683-97.

25) Joiner TE, Katz J (1999) Contagion of Depressive Symptoms and Mood: Meta-analytic Review and Explanations
From Cognitive, Behavioral, and Interpersonal Viewpoints. Clin Psychol (New York) 6, 149-64.

26) Song Z, Foo MD, Uy MA, Sun S (2011) Unraveling the daily stress crossover between unemployed individuals and their employed spouses. J Appl Psychol 96, 151-68.

27) Fowler JH, Christakis NA (2008) Dynamic spread of happiness in a large social network: longitudinal analysis over 20 years in the Framingham Heart Study. BMJ 337, a2338.

28) Kassenboehmer SC, Haisken-DeNew JP (2009) You're fired! the causal negative effect of entry unemployment on life satisfaction. Econ J 119, 448-62.

29) ten Brummelhuis LL, Haar JM, van der Lippe T (2010) Crossover of distress due to work and family demands in dual-earner couples: A dyadic analysis. Work Stress 24, $324-41$.

30) Lee GR, Shehan CL (1989) Retirement and marital satisfaction. J Gerontol 44, S226-30.

31) Spector PE, Cooper CL, Poelmans S, Allen TD, O'Driscoll M, Sanchez JI, Siu OL, Dewe P, Hart P, Lu L (2004) A cross-national comparative study of work-family stressors, working hours, and well-being: China and Latin America versus the Anglo world. Person Psychol 57, 119-42.

32) Aryee S, Fields D, Luk V (1999) A cross-cultural test of a model of the work-family interface. J Manage 25, 491-511.

33) Lu L, Gilmour R, Kao SF, Huang MT (2006) A cross-cultural study of work/family demands, work/family conflict and wellbeing: the Taiwanese vs British. Career Dev Int 11, 9-27.

34) The Korean labour market : some historical macroeconomic perspectives. [Internet]. International Labour Office. 2010 [cited 15 December 2014]. Available from: http://www.ilo. org/employment/Whatwedo/Publications/working-papers/ WCMS_142561/lang--en/index.htm.

35) Kroenke K, Spitzer RL, Williams JB (2003) The Patient Health Questionnaire-2: validity of a two-item depression screener. Med Care 41, 1284-92. doi:10.1097/01. MLR.0000093487.78664.3C. PubMed PMID: 14583691.

36) Stieglitz RD (2010) [Assessment of depressive disorders]. Ther Umsch 67, 549-53. doi:10.1024/0040-5930/a000093. PubMed PMID: 21043013.

37) McMahon JM, Pouget ER, Tortu S (2006) A guide for multilevel modeling of dyadic data with binary outcomes using SAS PROC NLMIXED. Comput Stat Data Anal 50, $3663-$ 80 .

38) Schaer M, Bodenmann G, Klink T (2008) Balancing work and relationship: Couples coping enhancement training (CCET) in the workplace. Appl Psychol 57, 71-89. 
Supplementary Table 1. The results of multiple logistic regression among dual-earners families after adjusting for age, body mass index, house hold income and own weekly working hours

\begin{tabular}{|c|c|c|c|}
\hline & $\mathrm{AOR}^{*}(95 \% \mathrm{CI})$ & $\mathrm{AOR}^{*}(95 \% \mathrm{CI})$ & $\mathrm{AOR}^{*}(95 \% \mathrm{CI})$ \\
\hline & Male & Female & \\
\hline \multicolumn{4}{|c|}{ Depressive symptoms } \\
\hline \multicolumn{4}{|c|}{ Spouse's weekly working hours } \\
\hline$<40$ hours & 1 & $1.08(0.83-1.40)$ & 1 \\
\hline $40-50$ hours & $1.02(0.78-1.34)$ & $1-$ & $0.98(0.76-1.27)$ \\
\hline $50-60$ hours & $0.85(0.58-1.24)$ & $1.06(0.82-1.37)$ & $1.05(0.79-1.40)$ \\
\hline$\geq 60$ hours & $1.22(0.91-1.64)$ & $1.29(1.03-1.62)$ & $1.34(1.04-1.73)$ \\
\hline$P$ value for trend & 0.340 & 0.001 (40 hours or above) & 0.007 \\
\hline \multicolumn{4}{|l|}{ Suicidal ideation } \\
\hline \multicolumn{4}{|c|}{ Spouse's weekly working hours } \\
\hline$<40$ hours & 1 & $1.01(0.78-1.31)$ & 1 \\
\hline $40-50$ hours & $1.03(0.79-1.34)$ & $1-$ & $0.99(0.76-1.29)$ \\
\hline $50-60$ hours & $1.04(0.74-1.45)$ & $1.19(0.92-1.54)$ & $1.23(0.93-1.63)$ \\
\hline$\geq 60$ hours & $1.30(0.99-1.71)$ & $1.32(1.05-1.66)$ & $1.40(1.09-1.80)$ \\
\hline$P$ value for trend & 0.079 & 0.002 (40 hours or above) & 0.001 \\
\hline
\end{tabular}

*Adjusted Odds Ratio 